\title{
Anabases
}

ANABASES Traditions et réceptions de l'Antiquité

$25 \mid 2017$

Varia

\section{Bruce LINCOLN, Politique du paradis. Religion et empire en Perse achéménide}

\section{Corinne Bonnet}

\section{OpenEdition}

\section{Journals}

Édition électronique

URL : http://journals.openedition.org/anabases/6146

DOI : 10.4000/anabases.6146

ISSN : 2256-9421

\section{Éditeur}

E.R.A.S.M.E.

\section{Édition imprimée}

Date de publication : 1 avril 2017

Pagination : 294-295

ISSN : 1774-4296

\section{Référence électronique}

Corinne Bonnet, "Bruce Lincoln, Politique du paradis. Religion et empire en Perse achéménide ", Anabases [En ligne], 25 | 2017, mis en ligne le 01 avril 2017, consulté le 20 janvier 2021. URL : http:// journals.openedition.org/anabases/6146; DOI : https://doi.org/10.4000/anabases.6146

Ce document a été généré automatiquement le 20 janvier 2021.

(c) Anabases 


\title{
Bruce LINCOLN, Politique du paradis. Religion et empire en Perse achéménide
}

\author{
Corinne Bonnet
}

\section{RÉFÉRENCE}

Bruce LINCOLN, Politique du paradis. Religion et empire en Perse achéménide (Histoire des

religions 2), Genève,

Labor et Fides, 2015 (éd. or. anglaise, Leuven, Peeters, 2012), 142 p.,

20 euros / ISBN 978-2-8309-1570-9

1 Éminent historien des religions à Chicago, Bruce Lincoln propose ici une analyse originale et passionnante des relations entre empire, religion et politique dans le monde perse. Ces textes émanent de conférences données au Collège de France et montrent comment l'imaginaire politique construit une représentation du pouvoir autour de la notion de " paradis » (en grec paradeisos), cet espace clos qui rassemble toutes les espèces animales et végétales, ce microcosme qui subsume la diversité de l'empire et qui renvoie à la création originelle et parfaite du dieu Ahura Mazda, protecteur des Grands Rois. Le paradis est la métaphore d'un empire solidement tenu par le roi, rassemblé autour du pivot que constituent la capitale et le roi, et capable de réunir, en vertu d'une ambition englobante et universalisante, la variété des peuples, des animaux, des arbres et des plantes, bref du vivant. Pour construire son parcours, B. Lincoln sollicite une grande variété de sources, comme les inscriptions royales perses, les traités zoroastriens de mythologie, les textes des historiens grecs, divers passages de l'Ancien Testament, de sorte que ce livre est susceptible d'intéresser un large public d'antiquisants ou d'historiens des religions.

2 Le volume contient quatre sections thématiques : 1. " À la recherche du paradis perdu »; 2. "La vérité du roi »; 3. "L'espace, le mouvement et le climat dans l'imaginaire achéménide »; 4. « Il faut cultiver notre jardin : de l'horticulture et de l'impérialisme Achéménide », avec un appendice sur " La mythologie zoroastrienne 
des plantes ». Le volume est doté d'un glossaire et d'une liste des sources. On signalera aussi aux p. 7-14 le bel et riche " Avant-propos des éditeurs ", Daniel Barbu et Nicolas Meylan, qui mettent très bien en évidence le parcours et les qualités propres de la démarche de B. Lincoln, en particulier ce " comparatisme linguistique " qui fait toute la valeur de son approche au plus près des sources, mais avec une ampleur d'analyse rare qui lui permet, en partant des discours, d'en décoder les usages stratégiques, c'està-dire politiques, économiques, sociaux. Or, précisément, le "paradis " est une production discursive hautement idéologique, comparable à celles que nos sociétés contemporaines secrètent. C'est pourquoi on adhérera sans réserve au constat des éditeurs (p.10) : "L'histoire des religions devient, dans cette perspective, un outil critique qui permet de réfléchir sur le monde dans lequel nous vivons. » À travers la notion de paradis, ce sont donc les mécanismes d'autorité, transcendante et éternelle, qui sont décodés. En effet, l'institution perse que ce mot recouvre renvoie à une cosmologie et sotériologie, d'une part, à une idéologie du pouvoir impérial de l'autre.

Lieu de perfection et de protection (le terme désigne au départ le mur d'enceinte qui entoure un territoire), le paradis engage tout le processus qui permet à Ahura Mazda d'établir sur terre le bien-être, la paix, la vérité ; c'est donc un espace de " recréation ", souvenir du monde tel qu'il fut, trace d'un bonheur originel que l'Empire perse entendait restaurer par le biais de la pax persiana. On recommande vivement la lecture de cet ouvrage virtuose.

\section{AUTEURS}

\section{CORINNE BONNET}

UT2J, PLH-ERASME

cbonnet@univ-tlse2.fr 